\title{
De um Prosaico Coexistir Interespecífico aos Dilemas do Biopoder: as interações humanas e não humanas no mundo urbano contemporâneo amazônico
}

\author{
Flávio Leonel Abreu da Silveira \\ Universidade Federal do Pará/UFPA, PA, Brasil \\ E-mail: flavio.leonel@pq.CNPq.br
}




\section{Resumo}

Neste artigo pretende-se contribuir para o debate acerca de questões relativas à convivência entre humanos e não humanos no âmbito da casa humana, de maneira a refletir sobre o coabitar interespecífico e as suas implicações nos campos da saúde humana e animal. Sendo assim, parte-se de uma experiência pessoal de convívio com gatos domésticos como animais companheiros (Haraway, 2010), trazendo à tona questões relacionais de caráter intersubjetivo, especialmente aquelas ligadas às formas de socialidade presentes quando se pensa a associação/ constituição de "coletivos híbridos" (Latour, 2008) na cidade.

Palavras-chave: Interespécies. Gatos. Habitar. Saúde. Cidade. Amazônia.

\section{Abstract}

In this article I intend to contribute to the debates concerning human and nonhuman coexistence within the human dwelling, aiming at the reflections on the interspecific cohabitation and its implications as in the fields of human and animal health. Thus, I discuss my own experience of living with domestic cats as companion animals (Haraway, 2010, shedding light on relational and intersubjective issues, especially those associated to the forms of sociability that come into attention when we reflect about the association/constitution of "hybrid collective "(Latour, 2008) in the city.

Keywords: Interspecies. Cats. Dwell. Health. City. Amazon. 


\section{Coabitar Interespecífico na Cidade}

$\mathrm{O}$ s motivos que me levaram a refletir sobre o tema deste artigo mesclam os meus interesses acadêmicos, especialmente aqueles concernentes às relações interespecíficas que contribuem para a produção de "coletivos híbridos" (Latour, 2008) no mundo urbano contemporâneo, com questões subjetivas no sentido de que o seu tema diz respeito diretamente a dimensões de minha trajetória pessoal e ao cotidiano que experiencio como habitante da/na cidade - neste caso, a cidade de Belém (PA), situada no Norte do País - especialmente, em relação às outras sensibilidades de caráter não humano com as quais interajo.

Logo, tratarei aqui de experiências intersubjetivas cotidianas implicadas na ordem do vivido, circunstanciais, portanto, pelo fato de que abordo questões relativas ao meu coabitar com felinos domésticos (Felis catus) no apartamento em que resido. Tais ponderações envolvem alguns aspectos de ordem simbólico-práticos que se referem à manutenção de minha saúde em termos psicossomáticos. Sendo mais direto, volto-me ao ato de compartilhar o espaço existencial (Norberg-Schulz, 1975) da morada desde as formas de socialidade (Sthratern, 1992; Maffesoli, 1987) que estabeleço com os meus gatos de companhia-ou, talvez, seja eu o seu humano de companhia - tocando diretamente o meu estar-no-mundo em-relação-com o Outro-animal, a partir daquilo que seria próprio ao sensível da vida social (Sansot, 1986), quando parto da presença de formas de associação que identificam uma situação de coexistência interespecífica, considerando, ainda, as suas implicações para a saúde humana. Nesse sentido, analiso um episódio ocorrido comigo envolvendo o meu bem-estar e que se relaciona diretamente aos gatos com os quais convivo. 
Se a proposta deste artigo passa, até certo ponto, por uma espécie de etnografia que considera o si-mesmo, preciso ressaltar que tal empresa não significa o equívoco de um subjetivismo narcísico que se regozija em falar de si. Pelo contrário, tomo a minha experiência como uma dimensão da vida social evidenciada nas inter-relações que estabeleço, tanto com os coletivos humanos quanto em relação aos não humanos numa cidade amazônica, a fim de pensar temas de ordem mais geral.

Sendo assim, o si-mesmo emerge como experiência de relação - de estar-junto com - aqui a referência ao pensamento de Maffesoli (1987) e de Haraway (2010) é direta - quando a alteridade é um construto/ vivência negociado no dia a dia da urbe. A referência ao si-mesmo do antropólogo (Ricoeur, 1994; Rocha; Eckert, 1995) é problematizada diante da figuração do outro como integrante de uma convivialidade (Illich, 1973) que me situa com e a partir de um coexistir social que aproxima as pessoas entre si, mas também, em relação aos não humanos - vegetais, animais, coisas - nas paisagens que são próprias ao universo urbano.

Nesses termos as implicações ético-morais, principalmente àquelas ligadas ao convívio com animais no espaço doméstico da morada, se por um lado evidenciam formas de socialidade que seriam da ordem do privado, por outro, se colocam à vida pública exatamente pelo âmbito da partilha do espaço citadino (Sennett, 1988), quando uma multiplicidade de inserções, agências e jogos sociais são colocadas em cena nos espaços praticados pelos agrupamentos humanos em interação. Uma complexidade deste nível é atravessada por tensões inerentes às complicadas relações entre vida privada e vida pública, quando a sua "articulação imprecisa" revela o postulado de que "a vida social e a vida pública se superpõem" - para me aproximar de Goffman a partir das reflexões trazidas por Joseph (2000, p. 8-14) sobre o trabalho do autor - engendrando formas sociais diversas e heterogêneas.

O artigo ao voltar-se à questão do compartilhamento da casa humana ${ }^{1}$ com gatos domésticos, busca cotejar e vislumbrar tais interações a partir da dinâmica das relações interespecíficas de caráter sensível, as quais estão presentes nas formas de socialidade humanas/não hu- 
manas, referidas ao coabitar o espaço existencial da morada - vinculado às noções de refúgio e de intimidade (Bachelard, 1988) - desde uma ecologia urbana ancorada na experiência ecosófica (Guattari, 1990) de conformar as complexas paisagens citadinas, com suas redes sociotécnicas heterogêneas configuradoras de sua malha urbana. A coexistência humana com a animalidade felina, desta forma, coloca em pauta uma ética própria à relação humano-animal com os riscos comuns que advém das liberdades e contingências (Brüseke, 1996), próprias às interações interespécies experimentadas pelos entes quando da constituição de coletivos plurais no corpo da urbe, afetando a experiência cotidiana dos sujeitos e, em nível mais prosaico - e, portanto, microssociológico - a minha existência como indivíduo urbano.

\section{O Antropólogo e seus Gatos, Intersubjetividade e Cotidiano na Urbe}

Optei por coabitar com animais de estimação. Aliás, desde a mais tenra idade morei em uma casa que possuía um grande quintal onde os animais domésticos conviviam com a minha família, especialmente cães e gatos, assim como, de alguma forma, os pequenos animais silvestres de vida livre que coexistiam no jardim e no pomar ambos cultivados com apreço por minha mãe, longe dos estilingues e de maustratos que costumava ver pelas cercanias.

Dessa forma, os animais de companhia sempre fizeram parte do meu cotidiano desde a infância, e mesmo depois de adulto, entre meus familiares e amigos que desfrutavam da presença dos "bichos de estimação" como companheiros de vida e de moradia, portanto interagir com eles sempre me pareceu uma experiência comum e constante em minha trajetória pessoal. Se, todavia, depois que passei a viver sozinho relutei por algum tempo em tê-los comigo em casa, era justamente pelo fato de que temia não poder dedicar-lhes à atenção necessária que exigem daqueles que os querem próximos, no entanto, cedi à vontade de "ter" um animal em casa e optei por adotar um gato.

Nina veio morar comigo porque ouvi o seu miado temeroso na rua, mais precisamente no estacionamento existente no condomínio do prédio em que moro. Pelo que tudo indica ela havia sido abandonada 
por alguém que não a queria consigo. Acuada, se escondera, sob um automóvel correndo o risco de ser atropelada caso o motorista desatento não a percebesse. À época não tinha mais que quatro meses de vida. Passado algum tempo estava nutrida, higienizada, medicada e castrada, compartilhando o mesmo teto comigo.

O processo terapêutico e de higienização era inevitável, pois ambicionava o convívio com ela em um nível de proximidade bastante grande: ela teria acesso às ambiências do apartamento; teria que ter o seu espaço de alimentação e de excreção, no mais poderia dormir e descansar onde quisesse. Mas, para que isso ocorresse seria necessário mediar - pelo menos até certo ponto - a relação que estabeleceria com ela de forma segura em termos de saúde, tanto para mim quanto para o felino que acolhia, pois coabitaríamos na mesma localidade do espaço doméstico a partir da minha decisão de trazê-la para o apartamento em que moro.

Nesses termos, as formas de controle do biológico e de assepsia do vivo, bem como as ações relativas ao biopoder tocam a minha existência humana muito de perto. Sujeito de camadas médias intelectualizadas e inserido numa cultura psi (Duarte, 1983; Velho, 1987; 1994) precisava lidar com o seu devir não humano, ou ainda, com as maneiras gatescas de como lidaria com o espaço concebido como morada por mim; com o locus para o exercício e a resolução de suas necessidades fisiológicas básicas, bem como com a sua sensibilidade enquanto um felino no mundo convivendo com um humano. Tudo isso, porque ambos nos descobríamos desde o nosso encontro, inseridos nas malhas interespecíficas e culturais constituídas por redes difusas e complexas, que nos englobam diante de suas interações sociotécnicas híbridas, seguindo as indicações latourianas (Latour, 2008).

Tais redes e condições sociotécnicas atravessadas pelo conhecimento biomédico e veterinário nos colocavam, senão o imperativo do biológico, pelo menos sob o meu ponto de vista, uma conveniência em lidar com este mesmo biológico pela via do controle das patologias, visando à coexistência na espacialidade do lugar da morada. Ou melhor, tratava-se de considerar aspectos relativos à assepsia e a medicalização como formas de lidar com as ambivalências próprias as questões do 
risco (Beck, 1997) - tão relevantes para as sociedades contemporâneas, diante das possíveis enfermidades e do sofrimento - e, por certo, com as intervenções médico-sanitárias que permitissem o meu convívio com ela, nesse jogo de alteridades humanas e não humanas que não excluem o universo dos germes recíprocos em interação e permuta diante de uma ecologia do microscópico.

Nossa relação mestiça de humano-felino que coexistem e que passam a coabitar o mesmo lugar praticado (Certeau, 1994) revelase um derivar juntos interespecífico, uma ecologia sutil do habitar a morada humana com o Outro, o animal de companhia, que não exclui as relações intraespecíficas - e, neste caso, por uma questão óbvia, da ordem das relações que são próprias da simbólica do animal humano que estabeleço com os meus vizinhos, com os veterinários, bem como com a minha irmã e os amigos que frequentam o meu apartamento quando em visita.

Alguns meses depois Ziggy surgiria como presente de um conhecido já que sabia que considerava Nina solitária demais. Também oriundo do meio urbano fora capturado quando descia pachorrento de uma árvore onde pernoitara. O mesmo processo higienizador foi realizado com ele visando o convívio, agora, não apenas comigo, mas, também, com Nina. Passado o processo de estranhamento inicial e a dinâmica adaptativa entre nós que seguiu à sua chegada, passamos a coabitar os três e constituímos o que considero uma família interespecífica, onde eu e ambos partilhamos o cotidiano do apartamento. A nós três soma-se a presença da senhora que três vezes por semana auxilia na manutenção e na organização do espaço doméstico, assim como nos cuidados com os meus dois companheiros ${ }^{2}$, sendo ela uma pessoa central para o bem-estar do nosso grupo familiar e a quem os felinos detêm um afeto especial, esperando-a junto à entrada do apartamento quando chega ao trabalho, bem antes dela inserir a chave na fechadura da porta ${ }^{3}$.

\section{O Processo Higienizador e o Convívio Interespecífico}

A meu ver não poderia ter deixado de castrá-los - tendo, também, realizado adaptações, por exemplo, colocar telas em todas as 
janelas. A problemática da castração se impunha à opção de viver com os animais no interior do apartamento. Portanto, as estratégias de biopoder (Foucault, 1982; Rabinow; Rose, 2006) passavam pela minha decisão - certamente, ligada às "ficções de segurança" (Beck, 1997, p. 23) - de realizar as intervenções cirúrgicas em Nina e Ziggy, visando a sua esterilidade. Sendo assim, o controle sobre os seus corpos passava pelo controle do meu - uma anatomo-política de domínio do corpo humano e dos não humanos - por questões que envolviam o convívio social, o exercício da cidadania e as problemáticas relativas à saúde pública. Percebia que pelo menos três motivos muito claros me levavam a autorizar a realização de um ato de caráter médicosanitarista sobre o corpo do Outro não humano ${ }^{4}$ que assumiam uma importância (bio)ética,

O primeiro, diz respeito ao fato de que não poderia conviver com a constante cíclica de cios aos quais Nina vinha experimentando, o que a tornava extremamente estressada, fazendo com que, no meu ponto vista humano, sofresse. Os seus miados altos e a sua agitação transtornavam o cotidiano de um morador de apartamento que tem vizinhos de prédio e que, porventura, reclamam do barulho alheio, especialmente durante as madrugadas de sono depois de um dia de labuta.

O fato de morar no primeiro andar e próximo a um muro bastante alto onde transitam diversos gatos machos moradores das redondezas agravava a situação. A presença de seus pretendentes que vagabundeavam nos telhados alheios - com seus odores, miados cortando a paisagem sonora à noite, e o que considerava um "namoro" a distância desde a janela da sala do apartamento até o muro na rua - estimulava o sistema hormonal da fêmea, tornando-a receptiva sexualmente. Tal situação fazia com que produzisse hormônios que desencadeavam sucessivos cios em minha companheira felina, diante dos apelos dos machos ao acasalamento, o que acarretava comportamentos irritadiços; as constantes posições de cópula e, principalmente, os sons que me despertavam à noite e, certamente, os vizinhos de andar. Uma etologia da sexualidade felina me forçava a lidar com sensibilidades outras.

Por outro lado, temia que a partir de suas escapulidas trouxesse consigo mais dois "problemas" 
castração: um que é relativo à condução/transmissão de possíveis zoonoses para o interior de casa, afetando a sua saúde e, assim, podendo comprometer a minha, constituindo uma questão da ordem da vida privada. O outro, por sua vez, se refere ao fato de que sendo muito jovem ela poderia conceber muitas "ninhadas", o que me colocaria na situação de encontrar quem adotasse os filhotes, o que nem sempre é fácil. Certamente, caso eu não tivesse consciência dos problemas produzidos pelo abandono de animais, seria mais um a contribuir para o aumento de gatos nas ruas, como é extremamente comum acontecer no mundo urbano belenense, o que além de ferir a própria dignidade do animal, suscita transtornos de caráter público, afetando os humanos.

O contexto urbano em que resido está situado nas cercanias de um Jardim Botânico - o Bosque Rodrigues Alves ${ }^{6}$ - detentor de rica fauna nativa da Amazônia paraense. Ao longo de minhas caminhadas no interior da área de conservação tenho observado a presença de felinos asselvajados convivendo com a fauna local e aquela confinada nos recintos, já que existe um pequeno zoológico com espécies nativas no local.

Durante a conversa com um dos biólogos responsáveis pelo bosque, ele mencionou que um dos problemas existentes no manejo da área seria a constante presença de gatos domésticos, os quais são descartados pela população no local. Em conversa com uma estagiária estudante de Zootecnia que atua no bosque, obtive a informação de que há preocupação com as interações entre os felinos em liberdade e os animais em cativeiro, pois o contato dos animais poderia desencadear a transmissão de zoonoses. De fato, trata-se de um problema palpável, pois certa vez observei um pequeno gato livre interagindo com um sagui una (Saguinus niger) em cativeiro.

Por outro lado, a constante presença de "gatos ferais" em uma área urbana voltada à conservação da biodiversidade nativa, indica a existência de um problema ambiental significativo para a proteção da biodiversidade urbana, pois a existência de espécies exóticas ao ambiente, neste caso uma espécie predadora, tende a gerar naquele espaço de conservação danos à fauna local, especialmente à avifauna e aos pequenos roedores nativos, mas também, os invertebrados que habitam o ecossistema urbano. 
Retomando o tema da castração, percebo que o caso de Ziggy era um pouco diferente. O problema das zoonoses persistia, porém, aliado aos sucessivos combates entre machos no período do cio próprio à etologia felina, que o trariam para casa certamente com diversos ferimentos - por vezes, verdadeiras mutilações, como se pode constatar em alguns casos - que o fariam sofrer podendo deixá-lo, inclusive, com marcas físicas com consequências estéticas. Além disso, poderiam estar associadas às doenças, implicando cuidados e gastos significativos em seu tratamento.

Finalmente, como um macho reprodutor ele dispersaria filhotes pelo mundo urbano, produzindo consequências muito mais de caráter público do que privado, pois as fêmeas não castradas pertencentes a outros humanos, ou mesmo, aquelas consideradas "de rua", conceberiam os seus filhotes contribuindo para aumentar o número significativo de gatos abandonados no bairro em que moro.

Diferentemente do argumento que considera a castração um atentado à liberdade animal - uma mutilação - penso que pelo contrário, trata-se de valorizar a sua liberdade e a de quem o quer perto de si com saúde, ao mesmo tempo em que indica a preocupação com o espaço público e o bem-estar dos animais de estimação - bem como, com a conservação da fauna silvestre. Primeiro, porque já que os domesticamos, o abandono dos animais nas ruas demonstra falta de ética para com o próprio animal em sua alteridade e existência digna, bem como com os humanos que partilham a vida na cidade com os animais abandonados a sua sorte.

Nesse sentido, é tanto um problema de cidadania ambiental - para usar uma expressão cara ao socioambientalismo - e de gestão do meio, neste caso aplicado àquela que seria a nossa casa, a cidade, quanto uma questão concreta ligada à saúde pública e ao oykos urbano, uma vez que os animais se reproduzem indiscriminadamente e contribuem para os sérios incômodos relativos à presença de zoonoses no mundo urbano contemporâneo, especialmente nas capitais brasileiras.

Por outro lado, castrá-los e mantê-los nutridos tende a minimizar a presença de "gatos ferais" cooperando para a extinção da fauna autóctone, tema relevante para a conservação da biodiversidade nativa existente nas poucas áreas verdes que restam na cidade de Belém, por 
exemplo, o que indicaria a possibilidade da extinção local de certas espécies pela presença de outras consideradas "invasoras"7.

Note-se que aqui há um dilema, sendo o gato um animal doméstico, argumentar que ele está fora de seu ambiente, quando nos referimos à cidade é um paradoxo - pois ele constituiria a ecologia da urbe - uma vez que a cidade é desde o mundo antigo o seu locus de existência a partir do convívio com os humanos, considerando a domesticidade da casa - o seu habitat por excelência - do quintal e da rua como espaços de deambulação e de civilidade na urbe. No entanto, quando pensamos na vida silvestre autóctone que a habita podemos perceber o gato - introduzido na América do Sul - como uma espécie invasora que adentra as áreas verdes e os parques, os espaços de conservação, as matas urbanas, entre outras, pois ao exercer o seu papel de predador quando participa da cadeia alimentar devorando organismos pertencentes à biodiversidade local, ele estaria deslocado do seu habitat, qual seja a casa humana.

Ora, o direito de dispor da vida do outro-animal e, assim, de optar por não castrá-lo para depois incorrer na prática de seu abandono (ou dos filhotes) nos espaços públicos em nome de uma pretensa liberdade, é uma forma de negar o seu bem-estar impondo-lhe, muitas vezes, uma vida de sofrimentos, penúrias e maus-tratos que contribuem para o seu adoecimento e o das pessoas que vivem em interação com eles, a partir de uma dinâmica ecológica própria à cidade.

Certa ética que promulga a liberdade reprodutiva do animal no contexto urbano parece-me, é justo o que impõe uma vida indigna aos seus descendentes - ou, às vezes, ao próprio animal que é abandonado - com consequências à conservação das espécies autóctones. Portanto, seria o caso de castrá-los ou, então, de assumir a responsabilidade sobre os seus filhotes ${ }^{8}$, criando-os a fim de destiná-los a pessoas que os adotem e criem com o respeito à sua diferença, que, todavia, implica a sua existência como seres sencientes (Bekoff, 2010) compartilhando o mundo com os humanos. Foi pensando nestas diversas situações que autorizei a castração de ambos e arquei com os custos financeiros da intervenção cirúrgica, menciono isto, porque a questão econômica parece ser por vezes um dos impeditivos da castração como intervenção de caráter tanto (bio)ético quanto profilático. 


\section{Descobrir-se Doente: o diagnóstico e o estigma}

Naquela tarde como de costume eu lia. Perto de mim os dois felinos velavam o meu silêncio, solidários com o meu ofício exigiam de mim apenas a companhia, uma presença afetiva lembrada, por vezes, pelo roçar de cabeça a comunicar um querer bem e a vontade de estar perto, solicitando um afago ou uma palavra de carinho. Meus olhos voltados ao livro e a seu universo de ideias fixavam nele a minha atenção na tarde quente equatorial, quando a modorra dos gatos que descansavam próximos dava-me a sensação de segurança emocional fruto de um estar-junto que enchia a domesticidade da casa de tranquilidade, tão necessária a minha saúde mental e ao meu bem-estar como humano. Portanto, as suas vidas pacíficas e nutridas tanto de alimentos quanto de carinho - ou seja, o seu bem-estar - revela-se fundamental para o meu estar no mundo como sujeito em relação seja com os humanos, ou com os não humanos.

De repente percebi no meu campo de visão alguns pontos negros que se deslocavam parecendo insetos que vagassem ao meu redor. Tentei inutilmente espantá-los, todavia permaneciam por ali. Estranhei a presença de insetos, pois necessariamente precisariam passar incólumes pela sensibilidade felina atenta a tudo o que vibra, sonoriza e se move ao seu redor. Continuei lendo. Outros insetos continuariam a aparecer e em vão os espantaria. Notei que estavam sempre relacionados ao meu olho direito.

Descobriria depois, consultando a internet ${ }^{9}$, tratar-se do fenômeno denominado de "moscas volantes", formas que lembravam pequenos insetos que pairavam "diante" do meu olho, mas que estavam na verdade relacionados à fisiologia do globo ocular (entoptic phenomenon), portanto, a questão não estava fora, mas dentro do olho. Entretanto, logo tais pontos se transformariam numa espécie de mancha opaca na minha visão, "deslocando-se" à medida que movia o olho. Havia pontos dispersos acompanhados de certo embaçar da vista, onde se destacava uma imagem filamentosa que remetia às marcas de um filme fotográfico queimado. Fiquei preocupado. Pontos na visão sempre surgem, mas somem. No entanto, intuí que estava com um problema de saúde e cheguei a pensar que havia, por algum motivo, descolado a retina. 
Fui ao hospital universitário onde conversei com um oftalmologista. Segundo informou seria necessário uma série de exames clínicos, mas infelizmente o aparelho do hospital estava danificado. Fui encaminhado a uma clínica na qual realizaria os exames para depois seguir ao seu consultório. Durante os exames minhas pupilas foram dilatadas com um colírio, meus olhos escrutinados por aparelhos quando luzes invasivas alcançavam o fundo dos meus olhos, que foram fotografados, registrados; anotações realizadas. Estava eu ali, corpo-olho-despersonalizado diante de um médico com sua parafernália tecnológica, que avaliava o meu estado de saúde: "A retina está bem! Tudo indica que você está com toxoplasmose!"

Quando recebi a notícia foi inevitável pensar em Nina e Ziggy. Mencionei ao médico e a seu assistente o fato de que coabitava com gatos, externando a minha ignorância em relação ao contágio. A reação facial e as considerações de ambos - Ahhhhhh!; Você tem gatos, está explicado! - revelaram a causa do meu problema oftalmológico, do meu adoecimento. Ambos estavam convencidos disso. Meus gatos eram os vilóes porque figuravam naquele contexto médico como os vetores naturais do Toxoplasma gondii, o protista transmissor do mal que me afligia ${ }^{10}$. Não disseram, mas pairava no ar a necessidade de me afastar dos bichanos, talvez de não mais coabitar devido a uma questão de saúde. Todavia ainda era apenas uma suspeita.

Saí do consultório meio atordoado pelo excesso de luz que invadia minhas pupilas dilatadas e pela possibilidade de ter que me afastar dos meus afetos não humanos. Minha irmã que me acompanhava - uma "gateira", expressão utilizada em alguns sites da internet para referir-se a quem aprecia a companhia de gatos, convivendo com dois deles em seu apartamento - tentou me consolar, dizendo que poderia não ser toxoplasmose e que "não é bem assim pra pegar a doença".

\section{A Consulta com o Oftalmologista: o antropólogo doente e os seus gatos de companhia}

Ao entrar no consultório médico percebi a presença de duas jovens vestidas com jaleco branco, logo compreendi tratar-se de estudantes do curso de medicina. Sorri e cumprimentei tentando ser simpático 
diante de uma atmosfera fria no calor equatorial. As estudantes permaneceram durante a consulta e não fui questionado se permitiria a sua presença ali, o que considerei pouco ético comigo, pois me pareceu que antes de qualquer coisa eu era percebido como paciente, portanto, jamais como alguém atuante ou detentor de qualquer agência que não aquela que me conduziu ao consultório "passivamente".

Entreguei ao médico o que considerei ser uma espécie de prédiagnóstico, pois os resultados dos exames ficariam prontos depois de alguns dias. O médico após pingar algumas gotas de colírio nos meus olhos solicitou que me posicionasse diante de um aparelho. As estudantes se aproximaram para observar as minhas pupilas dilatadas e os meus olhos afastados das órbitas por um aparelho, que evocou em mim a imagem de Alex portando os ganchos nos olhos durante o seu "tratamento" no filme A Laranja Mecânica, dirigido por Stanley Kubrick.

Foi quando o médico indicando às estudantes o problema mencionou: "Vocês estão vendo este vítreo aqui", onde despontava, segundo ele, "uma inflamação". Ficou claro que eu não era uma pessoa doente, mas sim um vítreo problemático, uma inflamação ocular evidente. Enquanto me examinava perguntou: "aquele antropólogo está na moda ainda... Geertz?", demonstrando certa abertura dialógica e interesse pelo meu ofício. Tentei responder algo sobre a questão, mas fui interrompido por uma instrução de como deveria me posicionar junto ao aparelho, e a conversa sobre "o antropólogo" se perdeu em meio a observações e conclusões objetivas acerca do meu olho direito doente.

Senti-me uma espécie de cobaia de experimento sendo observada pelos seis olhos que identificavam um "vítreo" numa face que oscilava entre o constrangimento e certa aflição, certamente pela minha ignorância em relação ao meu estado de saúde. Portanto, ele olhava meu olho - perscrutando-o, avaliando-o - enquanto eu exercia minha própria hermenêutica inspirada no antropólogo mencionado anteriormente por ele, acerca de sua forma de lidar comigo enquanto uma pessoa doente, com o meu corpo enfermo em meio aos meus dilemas existenciais. Estabelecia uma interpretação sobre o seu agir médico e o que restava era o meu olho embaçado de paciente coisificado ${ }^{11}$.

Diante do pré-diagnóstico de seu colega e de sua própria avaliação sobre o caso, constatou que o mal que me afligia era mesmo toxoplas- 
mose. Ponderou que nem precisaríamos esperar o resultado final dos exames - que posteriormente, confirmaria tratar-se do mal - para iniciarmos o "ataque" à doença. Indicou um número assustador de remédios e vários exames que deveria realizar aos quais me submeti buscando a eficácia do tratamento ao longo de semanas.

Durante a consulta mencionei que coabitava com dois gatos. A sua reação, assim como a das estudantes foi de desagrado. Disse que eu tinha "um problema", seguindo-se o comentário: “Tenho uma sugestão para os seus gatos! Pegue um saco e jogue-os no Guamá12!"

Fiquei perplexo diante do trio e argumentei consternado: “Mas eu amo eles... Eles são a minha família!"

Diante de uma afirmação tão subjetiva, devo ter sido considerado um sujeito emocional demais, beirando ao ridículo. Ele riu, as estudantes fizeram o mesmo, como sinal de conivência com uma brincadeira de mau gosto, que expressava um pensamento pragmático comigo e pouco ético com os animais. Pairou um silêncio eloquente que dizia tudo acerca da sua perspectiva sobre as relações entre humanos e felinos domésticos quando se trata de um caso de toxoplasmose.

Saí do consultório bastante abalado. É lógico que estava preocupado com a minha saúde, mas o que me causava mal-estar era a possibilidade de ter que me afastar de ambos os gatos. Entrei em um processo de sofrimento emocional e, sinceramente, considero que meus amigos perceberam que havia algo estranho acontecendo, porque solicitavam a minha companhia com miados, permaneciam próximos de mim como se sentissem o meu desconforto, que de alguma forma passava pela sua existência.

Em outras consultas eu constatava a minha melhora ao mesmo tempo em que ouvia do médico coisas como: "E as suas gatinhas?... Você que deve decidir, pois o seu problema está em casa..." Ou ainda: "Já mandou matá-las?" Se na primeira vez ficara chocado com a sua colocação e, de certa forma, me aborrecera pelo que dissera custandome real desconforto, agora, diante do tom de sua fala acompanhado do riso jocoso, obviamente, sabia que não esperava que os sacrificasse, mas que se posicionava preconceituosa e contrariamente à permanência de ambos em minha moradia. Nessa altura já havia visitado o médico veterinário e a minha posição sobre o "meu problema" havia mudado. 


\section{A Consulta ao Veterinário e a Perspectiva Diversa acerca do Outro-animal}

Estava bastante deprimido no dia que os levei ao veterinário para a consulta de rotina. Contei ao profissional sobre a situação em que me encontrava, deixando clara a posição do médico oftalmologista em relação aos animais e ao fato de manter a coabitação com os felinos, como um doente portador de toxoplasmose.

A posição do médico veterinário mostrou-se contrária àquela do oftalmologista. Havia, nesse caso, uma evidente divergência entre ambos sobre o adoecer humano e acerca da questão animal. Se o olhar que o primeiro lançava ao meu problema de saúde e a participação de meus companheiros no processo de adoecimento não eram compatíveis com o que o outro profissional defendia, tratava-se pelo que tudo indica, de um duplo problema de bioética que afetava a minha existência - com significativas consequências para a minha saúde em termos psicossomáticos - e as vidas dos gatos de companhia, tanto no sentido da manutenção de seu bem-estar quanto do convívio intersubjetivo comigo, e deles entre si. O que estava em jogo era a continuidade de uma vivência familiar interespécies.

De acordo com o médico dos meus companheiros, alguns oftalmologistas desconhecem a biologia do Toxoplasma gondii, especialmente o seu ciclo reprodutivo, fazendo com que tenham, segundo as suas palavras, "preconceitos contra os gatos". Informou-me que há, inclusive, debates calorosos em congressos sobre o tema "toxoplasmose", quando os veterinários se posicionam contra a postura médico-oftalmológica em relação aos animais, esclareceu. Citou, inclusive, o exemplo de uma colega veterinária que certa vez entrou em um debate acirrado sobre a questão com os profissionais oftalmologistas.

O profissional mencionou que havia uma possibilidade, ainda que remota, de eu ter adquirido a criatura microscópica quando realizava a higiene do local onde os animais evacuam, por inalação de esporos. Explicou que o ciclo reprodutivo do micróbio ocorre apenas uma vez nos intestinos do animal - que é o hospedeiro definitivo do parasita e que o felino participa na dispersão/eliminação dos oocistos através de suas excretas, podendo assim atingir os humanos - que neste caso, 
também são hospedeiros definitivos. Portanto, eu teria que ter tido o azar de ter inalado os esporos provenientes das fezes dos gatos, justo nesta situação única - o que poderia ser possível, obviamente. Caso tivesse sido assim, eles não me causariam mais nenhum dano desta ordem e eu não necessitava me afastar dos bichanos.

Vislumbrei a partir do meu problema de saúde a existência de um conflito entre escolas médicas, cujas perspectivas partiam de posições diversas em relação ao ciclo reprodutivo do microrganismo parasita e das formas de seu contágio: uma defendia o olhar acerca do mal que me afligia desde a biologia felina (com o foco nos intestinos dos animais) e a outra a partir de uma biologia humana (centrada no globo ocular do sapiens). De certa forma, o meu corpo apresentava-se como uma arena de batalha - um locus atravessado pelo biopoder com desdobramentos éticos para o corpo do Outro-animal.

Ora, o dilema referia-se às tensões entre campos científicos que manifestavam forças dicotômicas reificadoras das oposições entre a natureza (pela influência felina e o seu organismo-animal inserido no ciclo reprodutor do microrganismo) e a cultura (eu enquanto ser detentor de um corpo e seus significados, atrelado a um organismo com uma estrutura anatômico-fisiológica), ambas mediadas pelas tecnociências desdobradas no conflito de pontos de vista de profissionais vinculados às biomedicinas animal e humana, especialmente quando se tratava de lidar com a biologia do terceiro incluído, o Toxoplasma gondii.

O problema é que desde uma espécie de ecologia humana na urbe com enfoque na saúde - ou das interações humanas com os não humanos domésticos no espaço da casa - era preciso pensar o contexto no qual o meu contato com os felinos possibilitara a transmissão do parasita e o desencadeamento do processo de adoecimento vivido por mim.

Segundo o veterinário, o consumo de carne malpassada poderia ser um dos motivos do contágio. O microrganismo presente no solo onde um felino contaminado evacuou e, posteriormente, em contato com as plantas pode ser absorvido por um animal fitófago como o gado bovino e permanecer na sua carne que, consumida desta forma, pode transmiti-lo ao ser humano. Ele ainda faria uma brincadeira escatológica do tipo: "Você não comeu a carne dos seus gatos malpassada e nem comeu o cocô deles!" 
Ambas as imagens são fortes porque evocam a força do tabu e dos atos interditos, de relações impuras (Douglas, 1976). O fato de que não tenho por hábito comer carne de felinos e, muito menos crua, exclui a primeira possibilidade. Nota-se que aqui é inevitável à evocação da imagem dos "churrasquinhos de gato", tão presentes no imaginário brasileiro acerca dos espetinhos de carne assada vendidos nas ruas de várias cidades do país. Por mais que tal imagem paire como uma possibilidade na atmosfera urbana, a ingestão de carne felina não é tolerada, sendo ainda, por extensão, percebida como uma comida tabu no mundo ocidental, diferentemente de alguns países no contexto asiático (Podsberscek, 2009; Osório, 201 la). Além disso, não se trata de considerar à dimensão escatológica própria à coprofagia como prática alimentar. O que me parece é que pelo fato de que sempre convivi com felinos, talvez eu pudesse trazer comigo o parasita há anos e ele, por algum motivo (stress, por exemplo) manifestara a sua ação em meu globo ocular direito, somente naquele período de adoecimento. Por outro lado, poderia ter adquirido o patógeno através do consumo de água contaminada, de vegetais mal lavados, ou mesmo, pela ingestão de carne bovina malpassada.

Diante da melhora no quadro da doença - embora precise consultar semestralmente o oftalmologista - e da situação esclarecida pelo veterinário permaneci convivendo com os meus gatos. Todavia, a fim de evitar debates infrutíferos com o médico decidi dizer-lhe que havia "doado" os bichanos a amigos. Na realidade passei a conviver com o problema que permanece sob controle, e, portanto, não me aflige, ainda que o alien exista em mim como substrato orgânico para a sua existência.

\section{A Recidiva e a "Vontade de Saber"}

Passado um ano da descoberta da enfermidade e depois de ter obtido alta do tratamento, experimentei um processo de recidiva da doença. $O$ Toxoplasma voltava a manifestar a sua agência no meu organismo e, dessa vez, parecia bem ativo, porque minha vista ficou bastante turva. Voltei ao consultório do médico experiente que tratara 
do meu caso, sendo ele considerado um dos melhores na sua especialidade na capital. Ele, então, solicitou uma nova batelada de exames e receitou uma quantidade significativa de remédios, como ocorrera antes. Todavia, dessa vez, tudo isso veio acompanhado de uma colocação que me surpreendeu.

- "Você me desculpe, mas tenho que fazer uma pergunta", exclamou.

- Pois não, respondi.

- "Você faz parte do grupo de risco?"

Respondi, contrariado, que era gay. O fato de precisar falar de minha sexualidade não tem relação alguma com querer manter a minha identidade de gênero em segredo, ou seja, de permanecer no "armário" para usar uma categoria corrente. A questão é que não me sinto obrigado a fazê-lo a quem me questiona sobre isto e, além do mais, a indiscrição acerca da intimidade alheia tem a ver com o controle e uma "vontade de saber acerca" do outro, neste caso disciplinador. A questão de que o "armário" - assim como a gaveta - na concepção bachelardiana (1988) tem relação direta com os devaneios da intimidade, com aquilo que é mais precioso e, talvez, recôndito no sujeito desejante, necessariamente, não precisa ser aberto a qualquer pessoa. Não se trata de "enrustimento", mas de preservação do si mesmo como possibilidade, inclusive, de liberdade do ser.

Portanto, não se tratava de uma pergunta qualquer, pois havia implícita uma série de questões e de valores ligados ao "não-dito", que me situavam em um vasto campo ético-moral que oscilava entre o caráter profilático e o preconceito quase explícito. Além disso, acionava a velha "epistemologia do armário" como "dispositivo de regulação da vida" (Sedgwick, 2007, p. 20-25), como forma de exigir-me a verdade sobre o eu, confundindo o público e o privado. (Sennett, 1988)

- "Ah, eu não sabia disso!", concluiu.

Fiquei surpreso pelo fato de que parecia ser minha obrigação falar-lhe disso, como se ele devesse, necessariamente, saber acerca da minha sexualidade para tratar do meu olho. Não tardou a pedir que consultasse um infectologista, para ele "ficar mais tranquilo" em relação ao tratamento, deixando-me, certamente, pouco tranquilo uma 
vez que acenava sem mencionar sequer uma palavra a respeito, que eu poderia ser portador do HIV. Ora, o fato de ser gay e de ter uma recidiva de toxoplasmose não significa que eu seja soropositivo - havia feito dois exames ao longo do tratamento que haviam dado negativo, e além do mais estou informado sobre as formas de evitar o contágio do vírus HIV. A recidiva da toxoplasmose pode ocorrer mais de uma vez, dependendo do caso.

É corrente o fato de que soropositivos manifestam a toxoplasmose como uma das infecções oportunistas - como indicam Nissapatorn (2009); Brum et al. (2013), entre outros - e que ela pode ser um indicativo do adoecimento de AIDS. Todavia, tratava-se de um preconceito médico: a noção anacrônica de grupo de risco que ele acionou mostrava isso - quando, no meu ponto de vista, para correr risco basta estar vivo -, indicando uma visão equivocada em relação à transmissão do vírus. Nem eu como gay nem ele como heterossexual estávamos livres de nos contaminarmos através do sexo, simplesmente porque somos humanos e o vírus agiria indiferentemente em nossos organismos, por certo, com respostas distintas a ele.

O cuidado médico, aqui, está diretamente relacionado com o ato confessional de dizer o que se é, pois é preciso, diante de certos dispositivos de controle do corpo e da sexualidade, produzir uma discursividade acerca de si que enuncie ao outro uma verdade: sim sou isso; sim vivo em companhia daquilo, e assim por diante. A "homossexualidade" como signo de doença (ou do vir a tê-la) ainda persiste fantasmagórica no discurso médico-sanitarista de alguns profissionais, neste caso, como algo associado a certos males. Além disso, enquanto "dito" (Portinari, 1989) ela mostra-se como sendo mais que uma experiência, uma vez que se revela um discurso sobre a sexualidade, uma identidade manqué que, se porventura, escapa ao patológico no plano da construção da identidade de gênero, está necessariamente vinculada a ele no campo da saúde, pelo menos em certas perspectivas.

Não sei dizer em que nível há ignorância ou homofobia - ou, talvez, as duas juntas - em sua questão, mas, de qualquer forma a minha "homossexualidade" e a "animalidade" alheia (dos felinos) estavam par a par no âmbito da discriminação médica. Sinceramente, neste caso, sinto-me mais próximo dos gatos do que do humano, 
porque com os primeiros experimento a minha humanidade de maneira mais sensível já com o segundo sinto-me coisificado, reduzido a um punhado de estruturas orgânicas animadas por uma fisiologia, portanto, desumanizado.

Passado o tempo, considero que a minha experiência no mundo como existência pautada em uma vida com o Outro, desde a perspectiva de uma ecologia das formas de associação em que participam humanos e não humanos, tem se transformado para melhor a partir do momento em que decidi conviver com os felinos - talvez eu experimente, pelo convívio com eles, a possibilidade de me humanizar mais e melhor, ponderando acerca da simbólica de minha própria animalidade - que, agora, soma-se a presença de Nana e de Benedito, como os mais novos integrantes da família interespecífica humano-felinos.

Quanto ao Toxoplasma, ele está ali - encistado, mais ou menos ativo no meu organismo já que é um parasita intracelular obrigatório (Silva et al., 2007) -, figurando como uma experiência interespecífica visceral, que me leva semestralmente ao contato com o sistema médico. Persiste alheio ao corpo-receptáculo que sou eu, ainda que necessite dele, pois mesmo que habite este outro que possui consciência de si e dele, todavia, segue existindo em mim como potência e um devir.

\section{Notas}

1 Conforme Peter Burke (2009, p. 11) a casa “[...] es un punto de encuentro entre diferentes disciplinas: no sólo el diseño y la historia, sino también la arqueología, la antropología, la geografia e incluso la literatura"

2 Comumente trato-os como meus "filhos", dizendo-lhes, por exemplo: "venha aqui com o pai"; tratando-os por "meu amor", ou externando palavras carinhosas que traduzam o meu apreço por eles, aos quais respondem com miados, cabeçadas e afagos. Parto do princípio que humanizar os não humanos é um antropocentrismo sem o qual seria impossível se relacionar com eles desde a condição humana - a discussão é longa e não tenho pretensões de aprofundá-la no artigo -, começando pela própria simbólica humana de nominá-los. Para tanto, ver Milton (2005) e Borkfelt (2011). Sobre o tema da humanização dos animais para o caso brasileiro, bem como sobre as questões de cuidados, incluindo a castração e a medicalização, ver Osório (201lb) e Segata (2012).

3 O biólogo Rupert Sheldrake (2009) tem discutido intensamente aspectos da sensibilidade animal em relação aos seus afetos humanos - a percepção fina diante de determinados eventos; premonições; formas de comunicação sutis com as pessoas, entre outras - indicando o sensível como dimensão da coexistência humana/não humana. 
4 Lembro que o veterinário um pouco antes de realizar a intervenção cirúrgica em Nina solicitou que assinasse um documento, no qual permitia a realização da cirurgia de castração ao mesmo tempo em que me responsabilizava se, porventura, ela não resistisse ao processo operatório e viesse a perecer.

5 Problemas para mim é claro, que sou humano, esta condição que é minha. Portanto, trata-se de um problema de ordem intraespecífica e não de Nina, como não humana que tem as suas vicissitudes enquanto tal e suas próprias formas de habitar o mundo que compartilhamos como entes sensíveis.

6 Desenvolvo pesquisa intitulada "Estudo antropológico das interações dos humanos com os não-humanos no Bosque Rodrigues Alves na cidade de Belém (PA). Paisagens de evasão, conservação da biodiversidade e imaginário urbano", como projeto de Bolsa de Produtividade do CNPq.

7 Sobre a problemática relativa à predação de espécies nativas da fauna por carnívoros domésticos (especialmente cães e gatos), consideradas em diversos locais como espécies invasoras, ver Campos et al. (2007) e Silva-Rodríguez e Sieving (2011). A bibliografia sobre o tema é ampla.

8 Joanna Swabe (2005, p. 108) argumenta, para o caso holandês, que a prática da eutanásia de filhotes recém-nascidos tem diminuído em função do aumento da esterilização dos gatos, uma vez que tem se tornado a norma entre aqueles que possuem felinos como animais companheiros.

9 Como qualquer pessoa que possui acesso à internet não fujo ao que parece estar se tornando uma espécie de lugar comum, ou seja, a prática de procurar em sites informações sobre determinada doença, ou mesmo, para compreender os sintomas que indiquem a sua presença. No entanto, escapo da ideia de autocuidado, no sentido de tentar resolver o dilema de saúde simplesmente consultando-a, pois apenas a utilizei visando situar-me em relação ao que acontecia, até o momento de consultar um médico que me auxiliasse na resolução do problema. Sobre o tema do uso da internet e o autocuidado na saúde, ver Castiel e Vasconcellos-Silva (2002) e Vasconcellos-Silva e Castiel (2009).

${ }^{10}$ Conforme o artigo de Lehmann et al. (2006, p.11423), a presença e a dispersão do microrganismo pode ser entendida no seguintes termos: "Toxoplasma gondii is a protozoan parasite that infects nearly all mammal and bird species worldwide. Usually asymptomatic, toxoplasmosis can be severe and even fatal to many hosts, including people. Elucidating the contribution of genetic variation among parasites to patterns of disease transmission and manifestations has been the goal of many studies. Focusing on the geographic component of this variation, we show that most genotypes are locale-specific, but some are found across continents and are closely related to each other, indicating a recent radiation of a pandemic genotype. Furthermore, we show that the geographic structure of T. gondii is extraordinary in having one population that is found in all continents except South America, whereas other populations are generally confined to South America, and yet another population is found worldwide. Our evidence suggests that South American and Eurasian populations have evolved separately until recently, when ships populated by rats, mice, and cats provided T. gondii with unprecedented migration opportunities, probably during the transatlantic slave trade. Our results explain several enigmatic features of the population structure of T. gondii and demonstrate how pervasive, prompt, and elusive the impact of human globalization is on nature". Ainda, sobre a toxoplasmose, ver Negri et al. (2008) e Climeni e Monteiro (2009). 
11 Aqui não questiono a sua competência médica em tratar o meu problema de saúde, pelo contrário, ela é inquestionável e sou-lhe imensamente grato. Trata-se apenas de suscitar os antigos dilemas relativos à interação médico (ativo)-doente (paciente) pautada no modelo reducionista que percebe o órgão em si, ou a parte do corpo doente, perdendo de vista a pessoa como um todo biopsicossocial, portanto, a pessoa doente como, fenomenologicamente, um fato social total. (Mauss, 1974)

12 Rio que banha a cidade de Belém.

\section{Referências}

ALGER, Janet. M.; ALGER, Steven. Cat culture, human culture: an ethnographic study of a cat shelter. Society and Animals, Bedfordshire, v. 7, n. 3, p. 199-218, 1999.

BACHELARD, Gaston. A Poética do Espaço. São Paulo: Martins Fontes, 1988.

BECK, Ulrich. A reinvenção da política: rumo a uma teoria da modernização reflexiva. In: BECK, Ulrich; GIDDENS, Anthony; LASH, Scott. Modernização reflexiva: política, tradição e estética na ordem social moderna. São Paulo: Ed. UNESP, 1997. p. 11-71.

BEKOFF, Marc. A vida emocional dos animais. Alegria, tristeza e empatia nos animais: um estudo científico capaz de transformar a maneira como os vemos e os tratamos. São Paulo: Cultrix, 2010.

BORKFELT, Sune. What's in a Name? Consequences of Naming NonHuman Animals. Animals, Basel, v. 1, p. 116-125, 2011.

BRUM, Jorge Wilson A. et al. Parasitoses oportunistas em pacientes com o vírus da imunodeficiência humana. Rev. Bras. Clin. Med., São Paulo, v. 11, n. 3, p. 280-288, 2013.

BRÜSEKE, Franz J. Liberdade e risco. Papers do NAEA, Belém, n. 68, 1996. 13p.

BURKE, Peter. La historia social y cultural de la casa. Historia Crítica, Bogotá, v. 39, p. 11-19, 2009.

CAMPOS, Claudia. B. et al. Diet of free-ranging cats and dogs in a suburban and rural environment, south-eastern Brazil. Journal of Zoology, London, v. 273, p. 14-20, 2007.

CARRITHERS, Michael; BRACKEN, Louise J.; EMERY, Steven. Can a Species Be a Person? A Trope and Its Entanglements in the Anthropocene Era. Current Anthropology, Chicago, v. 5, n. 52, p. 661-685, 2011.

CASTIEL, Luís D.; VASCONCELLOS-SILVA, Paulo R. Internet e o autocuidado em saúde: como juntar os trapinhos? História, Ciências, Saúde, Manguinhos, Rio de Janeiro, v. 9, n. 2, p. 291-314, 2002. 
CERTEAU, Michel de. A Invenção do Cotidiano: artes de fazer. Rio de Janeiro, Vozes, 1994.

CLIMENI, Bruno S. O.; MONTEIRO, Marcos V. Toxoplasmose. Revista Científica Eletrônica de Medicina Veterinária, on-line, v. 7, n. 12, p. 8, 2009. Disponível em: <www.revista.inf.br>. Acesso em: $1^{\circ}$ out. 2015.

CRAPANZANO, Vincent. Réflexions sur une anthropologie des émotions. Terrain, [S.1.], p. 109-117, 1994.

DAMATTA, Roberto. A Casa e a rua: espaço, cidadania, mulher e morte no Brasil. Rio de Janeiro: Rocco, 1997.

DESCOLA, Philippe. Estrutura ou sentimento: a relação com o animal na Amazônia. MANA, Rio de Janeiro, v. 4, n. 1, p. 23-45, 1988.

DOUGLAS, Mary. Pureza e perigo. São Paulo: Perspectiva, 1976.

DUARTE, Luís Fernando D. Três ensaios sobre pessoa e modernidade.

Boletim do Museu Nacional, Rio de Janeiro, v. 41, n. 1-69, 1983.

DUARTE, Luís Fernando D. Investigação antropológica sobre doença, sofrimento e perturbação: uma introdução. In: DUARTE, Luís F. D.; LEAL, Ondina F. (Org.). Doença, sofrimento, perturbação: perspectivas etnográficas. Rio de Janeiro: FIOCRUZ, 1998. p. 9-27.

DUBEY, Jitender P.; LINDSAY, David S.; LAPPIN, M. R. Toxoplasmosis and Other Intestinal Coccidial Infections in Cats and Dogs. Vet. Clin. Small Anim., Philadelphia, v. 39, p. 1.009-1.034, 2009.

FOUCAULT, Michel. História da sexualidade I: a vontade de saber. Rio de Janeiro: Graal, 1982.

FUDGE, Erica. Animal. London: Reaktion Books, 2002.

GANE, Nicholas. When we have never been human, what is to be done? Interview with Donna Haraway. Theory, Culture \& Society, London, v. 23, n. 7-8, p. 135-158, 2006.

GUATTARI, Félix. As três ecologias. Campinas: Papirus, 1990.

GOFFMAN, Erving. A representação do eu na vida cotidiana.

Petrópolis: Vozes, 2007.

GRANDIN, Temple.; JOHNSON, Catherine. O bem-estar dos animais: proposta de uma vida melhor para todos os bichos. Rio de Janeiro: Rocco, 2010 .

HARAWAY, Donna. Manifeste des espèces de compagnie: chiens, humains et autres partenaires. Éditions de l'éclat, 2010. 
HOROWITZ, Alexandra C.; BEKOFF, Marc. Naturalizing anthropomorphism: behavioral prompts to our humanizing of animals. Anthrozoös, New York, v. 20, n. 1, p. 23-35, 2007.

ILLICH, Ivan. A convivialidade. Lisboa: Edições 70, 1973.

INGOLD, Tim. The Perception of the environement: essays livelihood, dwelling and skill. Londres: Routledge, 2000.

JOSEPH, Isaac. Erving Goffman e a microssociologia. Rio de Janeiro: Editora FGV, 2000.

KULICK, Don. Animais gordos e a dissolução da fronteira entre as espécies. MANA, Rio de Janeiro, v. 15, n. 2, p. 481-508, 2009.

LANDSBERG, Gary. Feline behavior and welfare. Animal Welfare Forum: The Welfare of Cats. JAVMA, Illinois, v. 208, n. 4, p. 502-505, 1996.

LATOUR, Bruno. Jamais fomos modernos. Rio de Janeiro: Ed. 34, 1994.

LATOUR, Bruno. Reensamblar lo social: una introducción a la teoria del actor-red. Buenos Aires: Manantial, 2008.

LEACH, Edmund R. Aspectos antropológicos da linguagem: categorias animais e insulto verbal. In: DAMATTA, Roberto. Edmund Leach. São Paulo: Ática, 1983. p. 170-198.

LEHMANN, Tovi et al. Globalization and the population structure of Toxoplasma gondii. PNAS, Irvine, v. 30, n. 103, p. 11.423-11.428, 2006.

LESTEL, Dominique. Portrait de l'animal comme sujet. Revue de synthèse, Paris, v. 4, n. 1, p. 139-164, 1999.

MAcDONOGH, Katharine. Histoire des animaux de cour. Paris: Petit Bibliothèque Payot, 2011.

MAFFESOLI, Michel. O Tempo das tribos: o declínio do individualismo nas sociedades de massa. Rio de Janeiro: Forense Universitária, 1987.

MAFFESOLI, Michel. Elogio da razão sensível. Petrópolis: Vozes, 1998.

MAUSS, Marcel. Sociologia e antropologia. São Paulo: EPU \& EdUSP, 1974. v. 2,

MULLIN, Molly. Mirrors and windows: sociocultural studies of humananimal relationships. Annu. Rev. Anthropol., Palo Alto, v. 28, p. 201-224, 1999.

MILTON, Kay. Anthropomorphism or egomorphism? The perception of non-human persons by human ones. In: KNIGTH, John (Ed.). Animal in person: cultural perspectives on human-animal intimacies. Oxford: BERG, 2005. p. 255-271. 
NISSAPATORN, Veeranoot. Toxomplasmosis in HIV/AIDS: a living legacy. Southest Asian J. Trop. Med. Public Health, Bangkok, v. 40, n. 6, p. 1.158-1.178, 2009.

NEGRI, Daísa de et al. Toxoplasmose em cães e gatos. Revista Científica Eletrônica de Medicina Veterinária," Garça, v. 6, n. 11, p. 7, 2008.

NORBERG-SCHULZ, Christian. Nuevos caminos de la arquitectura: existencia, espacio y arquitectura. Barcelona: Editorial Blume, 1975. p. 7-45.

OSÓRIO, Andréa. Alguns aspectos simbólicos acerca do gato. Revista ILHA, Florianópolis, v. 12, n. 2, p. 231-259, 2011 la.

OSÓRIO, Andréa. Humanidade e não-humanidade: notas sobre um grupo de protetores de gatos de rua. Trabalho apresentado no $4^{\circ}$ SEMINÁRIO DE PESQUISA DO INSTITUTO DE CIÊNCIAS SOCIAIS E DESENVOLVIMENTO REGIONAL, da Universidade Federal Fluminense UFF, Campos dos Goytacazes, RJ, 2011. Anais... Campos dos Goytazes, RJ, $2011 \mathrm{~b}, 17 \mathrm{p}$.

PARKER, James. N.; PARKER, Philip M. (Ed.). The official patient's sourcebook on toxoplasmosis: a revised and updated directory for the internet age. ICON Group International, 2002.

PODSBERSCEK, Anthony. Good to Pet and Eat: The Keeping and Consuming of Dogs and Cats in South Korea. Journal of Social Issues, Washington, v. 65, n. 3, p. 615-632, 2009.

PORTINARI, Denise. O discurso da homossexualidade feminina. São Paulo: Brasiliense, 1989.

RABINOW, Paul; ROSE, Nikolas. Biopower Today. BioSocieties, London, v. 1, n. 195-217, 2006.

RICOEUR, Paul. O Si-mesmo como outro. São Paulo, Papirus, 1994.

ROCHA, Ana L. C. da; ECKERT, Cornelia. O tempo e a cidade. Porto Alegre: Ed. da UFRGS, 2005.

SAITO, Carlos H. et al. A matança dos gatos na UnB: estilhaços da distância entre homens e animais. Rev. Eletrônica Mestr. Educ. Ambient, Rio Grande, v. 9, n. 124-136, 2002.

SANSOT, Pierre. Les formes sensibles de la vie sociale. Paris: PUF, 1986.

SEDGWICK, Eve K. A epistemologia do armário. Cadernos Pagu, Campinas, v. 28, p. 19-54, 2007.

SEGATA, Jean. Parecidos, o suficiente: nós e os outros humanos, os animais de estimação. Revista de Antropologia Social dos Alunos do PPGAS-UFSCar, São Carlos, v. 4, n. 1, p. 207-234, 2012. 
SENNET, Richard. O declínio do homem público: as tiranias da intimidade. São Paulo: Companhia da Letras, 1988.

SERPELL, James. A. Domestication and history of the cat. In: TURNER, Dennis C.; BATESON, Paul (Ed.). The domestic cat: the biology of its behaviour. Cambridge: Cambridge University Press, 2000. p. 179-192.

SERPELL, James A. Anthropomorphism and Anthropomorphic selectionbeyond the "Cute Response". Society and Animals, [S.l.], v. 10, n. 4, p. 437-454, 2002.

SHELDRAKE, Rupert. A sensação de estar sendo observado e outros aspectos da mente expandida. São Paulo: Cultrix, 2009.

SILVA, Bruno F. et al. Uma revisão sistemática sobre as formas de infecção do Toxoplasma gondii. Natureza, on-line, v. 5, n. 2, p. 63-67., 2007.

SILVA-RODRÍGUEZ, Eduardo A; SIEVING, Kathryn. E. Influence of Care of Domestic Carnivores on Their Predation on Vertebrates. Conservation Biology, [S.1.], v. 25, n. 4, p. 808-815, 2011.

STRATHERN, Marilyn. Parts and wholes. Refiguring relationship in a PostPlural World. In: KUPER, A. (Ed.). Conceptualizing society. Routledge: London and New York, 1992. p.75-104.

SWABE, Joanna. Loved to Death? Veterinary visions of pet-keeping in modern dutch society. In: KNIGTH, John. (Ed.). Animal in person. Cultural perspectives on human-animal intimacies. Oxford: BERG, 2005. p. $101-118$.

THOMAS, Keith. O Homem e o Mundo Natural: mudanças de atitudes em relação às plantas e aos animais (1500-1800). São Paulo: Companhia das Letras, 1988.

TUAN, Yi-Fu. Espaço \& Lugar: a perspectiva da experiência. São Paulo: DIFEL, 1983.

VASCONCELLOS-SILVA, Paulo R.; CASTIEL, Luís D. As novas tecnologias de autocuidado e os riscos do autodiagnóstico pela Internet. Rev Panam Salud Publica/Pan Am J Public Health, Washington, v. 26, n. 2, p. 172175, 2009.

VELHO, Gilberto. Individualismo e cultura. Rio de Janeiro: Jorge Zahar Ed., 1987.

VELHO, Gilberto. Projeto e Metamorfose: antropologia das sociedades complexas. Rio de Janeiro: Jorge Zahar, 1994. 